\title{
Setting up a Spatial Data Infrastructure (SDI) for the ROSELT/OSS Network
}

\author{
M. Ajmi1 ${ }^{*}$, M. H. Hamza1 ${ }^{*}$, M. Labiadh², M. Yermani3 ${ }^{3}$ N. Ben Khatra4, A. S. Al-Thubaiti1, \\ I. A. Moharrem¹, A. El Arrim \\ ${ }^{1}$ Department of Geography and Geographic Information Systems, Faculty of Arts, King Abdulaziz University, \\ Jeddah, KSA \\ ${ }^{2}$ Geomatics, Earth and Land Settlement Branch, Department of Geology, Faculty of Sciences of Tunis, Tunis EI \\ Manar University, Tunis, Tunisia \\ ${ }^{3}$ Geomatics Branch, Environmental Design Faculty, King Abdulaziz University, Jeddah, KSA \\ ${ }^{4}$ Environment Programme, Sahara and Sahel Observatory OSS, Tunis, Tunisia \\ ${ }^{5}$ Department of Geology, Faculty of Science and Technology of Tangier, Abdelmalek Essaâdi University, Tetuan, \\ Morocco \\ Email: ajmiajmi@yahoo.fr, mhhamza@kau.edu.sa
}

Received 27 December 2013; revised 21 January 2014; accepted 15 February 2014

Copyright (C) 2014 by authors and Scientific Research Publishing Inc.

This work is licensed under the Creative Commons Attribution International License (CC BY).

http://creativecommons.org/licenses/by/4.0/

(c) (i) Open Access

\section{Abstract}

Environmental monitoring and evaluation (M\&E) systems are indispensable tools for sustainable land management, especially in dry and fragile ecosystems. The reporting and dissemination of its products and indicators are the key roles to perform their missions. Furthermore, the overall success of such multilateral projects and networks depends on well-organized infrastructures for spatial data management. A spatial data infrastructure (SDI) is an efficient framework to centralize the management of spatial data and information related to multilateral projects for the best sharing and exchange between partners and stakeholders in order to ensure that they are interactively connected to use the data efficiently and in a flexible manner. This paper outlines the work undertaken in partnership between the Geography and GIS Department of the Faculty of Arts, King Abdulaziz University, Saudi Arabia Kingdom, the Geomatics, Earth and Land Settlement Branch of the Department of Geology, Faculty of Sciences of Tunis, Tunis El Manar University, Tunisia, and the Sahara and Sahel Observatory OSS which is an intergovernmental organization, in order to build a Spatial Data Infrastructure (SDI) for the ROSELT/OSS program (Long-Term Environmental Monitoring Observatories Network in the Circum-Sahara of the Sahara and Sahel Observatory). This SDI is entirely developed using Open Source technologies and the extensive suite of OGC (Open Geospatial Consortium) standards and specifications, to enable interoperability among and

*These two authors contribute equally. 


\title{
between its different components.
}

\section{Keywords}

\author{
SDI, Geospatial Data, Metadata, Geocatalogue, Webmapping, OGC
}

\section{Introduction}

Sustainable development requires access to data, information, knowledge and understanding about the environment and natural resources. Often referred to as geographical or spatial data, is the information tied to a specific location, this one is an indispensable part of the available knowledge at modern science of Information and Communication Technology.

The GIS technique is an effective tool making the data analyses easier to handle and providing high capabilities of dealing with large spatial data [1]. In Africa, especially in developing countries, mastering geographic information is a vital tool to optimize the exploitation of natural and human resources and to fight against environmental and social issues [2]. The geographic information can help African countries guide their development practices and decision making policies and to attract foreign investment. For those countries, the establishment of infrastructures for managing geographic information is as important as building roads, telecommunications networks and other public services.

We must therefore consider available resources for collecting, managing, sharing and using geospatial data as a basis for sustainable development, hence the concept of Spatial Data Infrastructure (SDI) that puts an emphasis on partnership and coordination to deliver geographic information to decision-makers and public at large in an easy-to-use format. This kind of application is increasingly necessary especially an inter-organizational environment which requires a high level of regional collaboration and in which all spatial data stakeholders (both users and producers) have to cooperate and utilize information and technologies in a cost-effective way. However those infrastructures are currently underutilized especially in Africa due to a number of factors: poor awareness of decision makers, unavailability of spatial datasets and insufficient human and technical resources. In this contribution, the aim is to design and set up a spatial data infrastructure for the ROSELT/ OSS (Long Term Ecological Monitoring in the Circum-Sahara of the Sahara and Sahel Observatory-OSS) in order to overcome inconsistencies in geographic data collection, lack of documentation, incompatibility of spatial datasets and to help centralize the management of the informational resources related to the program. This SDI is developed using a range of free and open source technologies and based on widely used open standards.

\section{The ROSELT \OSS Network}

The Sahara and Sahel Observatory (OSS) is an intergovernmental organization working on environment and sustainable development with twenty-two member countries in the peri-Saharan region, five non-African member countries and several sub-regional, regional and international organizations. It aims at building up an African arena for co-operation and exchange to combat desertification and poverty through a North South-South mutually profitable partnership.

OSS has launched the ROSELT programme. The name ROSELT comes from the French name of the network: "Réseau d'Observatoires de Surveillance Ecologique à Long Terme": a network for long term ecological monitoring observatories (Figure 1). ROSELT aims at promoting and supporting long term programmes for environment monitoring in arid zones affected by land degradation. Biodiversity management and the role of arid zones in relation to the global climate change and the combat against desertification are taken into proper account [3].

Since its launching at 1992, the network carries long-term environmental monitoring activities that span the circum-Saharan space, It aims specifically to improve the scientific understanding of the interactions between communities and the environment at the local level by collecting, analyzing and sharing reliable data on the state of the environment in the circum-Sahara and various biophysical and socio-economic indicators to enhance 


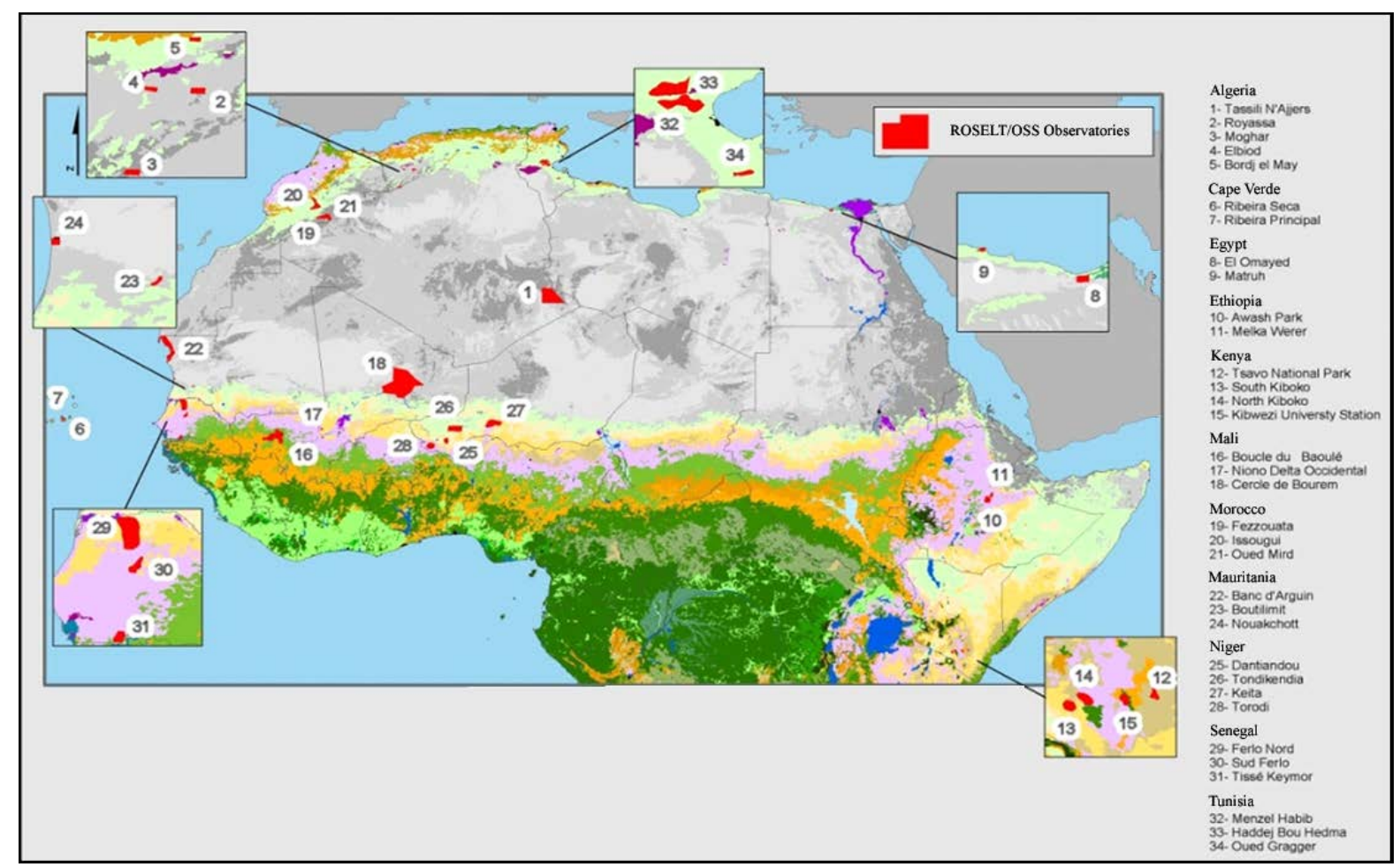

Figure 1. Location of the ROSELT/OSS observatories in Africa.

knowledge on the mechanisms, causes, consequences of desertification, loss of biodiversity and climate change.

The ROSELT/OSS network today comprises 25 observatories or clusters of observatories spread across circum-Saharan Africa and located in 11 countries. They were selected from a large number of candidate sites, following a rigorous scientific approach applied by an ad hoc committee between 1992 and 1994. Those selection criteria dealt with a study of the dynamics of ecological, land use and socio-economic systems.

Among the selected 25 ROSELT/OSS observatories, 12 were retained as pilot observatories to serve as "laboratories" where the ROSELT/OSS concept could be fine-tuned. There, data collection and processing techniques are perfected with a view to develop reliable decision-support tools, such as maps, indicators and information systems that could be later used more widely in the circum-Saharan region [4].

\section{Problem Statement: Data Management Issues in ROSELT}

The importance of information in decision making is crucial, especially with regard to the management and the monitoring of areas with risk of degradation. Indeed, data is the basic infrastructure enabling a solid foundation to any strategy for natural resource management and fight against the desertification.

Collection and dissemination of relevant, accurate and up to date information are actually of a paramount importance to improve the knowledge of the environment. Being able to access these data quickly is a prerequisite for the development of effective policies to fight against climate change related issues in particular and protecting the environment in general.

The rational exploitation of these data requires accurate documentation of collection methodologies and data production. The harmonization of methodologies for data collection is mandated by the establishment of regular and long-term natural resources monitoring devices and observatories as defined by ROSELT programme. On the other hand, the data generated by these observatories should be properly stored and managed in order to use it in an optimal way and ensure that it is accessible to potential users.

It is also important to note that data from different sources are often incomparable. Consistency and comparability of non-harmonized data is a major problem in their use by an environmental monitoring device.

In this regard, ROSELT data, collected during the activities of ecological monitoring in observatories (indicators, maps, statistics, publications...), have been accumulated over the years; the structuring and storage of 
this information exist in different formats. The current problem is the dissemination and the access to the shared information [5] because the situation is currently characterized by the following facts: Geographical dispersion and non-centralized management of resources, existing solutions that don't take into account the spatial characteristics of data, Limited access to resources for the network stakeholders and members, absence of information dissemination platform for the public at large.

The actual situation diagnosis shows that ROSELT is a fragmented organizational system which requires a high level of intergovernmental and regional collaboration. Different stockholders from various countries needs to work together closely and to agree on how they will store, use and make their data available to policy makers, researchers and the wider society. This collaboration is generally regarded as very difficult. In particular, organizational and technical issues are considered fundamental constraints to inter-organizational sharing of spatial data [6].

\section{Project Purpose: An SDI for ROSELT}

\subsection{Interactive Dissemination of ROSELT Resources}

Spatially referenced data are a basic part of environmental information systems and they are crucial to support policy makers and public participation within any environmental decision making process like ROSLET. However, these data are not always available to the public and are not usually in a format that is understood by all the different stakeholders

Using the information collected through the environment monitoring observatories provides big challenges in integrating and connecting the various information sources used and the technologies implemented.

Though environmental monitoring data are important inputs to evaluation models and decision-making systems, they are highly distributed and heterogeneous, and thus difficult to access in a coordinated manner. The first step to make them interoperable is to produce a spatial and temporal metadata registry that enables the science community to more easily use and exchange data and services [7].

Furthermore, centralizing storage and data exchange are keystones of any geographical information based project, such information must not only exist, but it is also essential to identify it easily, to know who can provide it, to get it effectively, and finally to know how it can be integrated with other information. Moreover, the success of those programs depends on a well-organized information system with metadata storage.

To solve the issues of management, dissemination and access to ROSELT data, the aim of this project is the establishment of a web-based spatial data infrastructure [8] to effectively manage the geographically distributed and growing datasets of ROSELT observatories network [9] and to promote the interactions between its various partners and members.

\subsection{Concept of Spatial Data Infrastructure}

The term "Spatial Data Infrastructure" (SDI) is often used to denote the relevant base collection of technologies, policies and institutional arrangements that facilitate the availability of and access to spatial data. The SDI provides a basis for spatial data discovery, evaluation and application for users and providers using a minimum set of standard practices, protocols, and specifications [10].

A spatial data infrastructure is an environment enabling a wide variety of users to easily access and retrieve spatial data sets in a complete, consistent, and secure manner and in which all stakeholders (both users and producers) can cooperate and utilize information and technologies in a cost effective way.

From an End User perspective, a SDI should organize information and resources and distributes them, and providing those services via a single location, often online. In both cases, through the SDI interface, the end user should find the resources he's searching via descriptive sheets called metadata.

SDI architectures have changed with the rapid advance of technology and the open standards infrastructure that enables the Internet and the Web. Geospatial data is still at the heart of every SDI, and data coordination will always be an important SDI activity. However, "technical interoperability" enabled by open standards has changed workflows and made institutional coordination easier [11].

\subsection{ROSELT-SDI Objectives}

The infrastructure is developed to meet an increasingly need felt by ROSELT partner institutions and stockhold- 
ers that want to promote the sharing and accessibility of the network resources and products.

This information system which integrates a map server, a metadata database and interaction policies is designed to ensure the coordination and dissemination of information between the involved partners of the project at different levels. Institutionally, it will contribute to the decompartmentalization of various structures involved in natural resource management and facilitate partnerships and synergies between stakeholders at local and international levels. Specifically, it allows:

- Data valorization by providing a better understanding of the existing and not easily accessible data in ROSELT observatories and details on how it can be used to meet a particular need, and under which conditions it can be acquired and used;

- Setting-up an observatory for environmental data (past, present and future) in the OSS intervention zone to enable combining spatial information from different sources for comparison and evolution analysis purposes;

- Providing a decentralized access and giving an uniform view to dispersed information to make it available via its metadata according to defined restrictions;

- To navigate, consult and download the data with the help of a query interface.

\subsection{Data and Users of ROSELT-SDI}

The environmental monitoring approach in ROSELT is based on a set of measurements and observations, and thus and repetitive acquisition of ecological data in the broadest sense, including socio-economic data interacting with the ecological data. Ecological monitoring is based on field measurements, complemented by remote-sensing data. Socio-economic monitoring via indicator and statistics are carried out in parallel with ecological monitoring because of the close links between the environment and its users.

A major goal of ROSELT/OSS is to provide these monitoring data and information to users, in the form of arguments, criteria and tools for decision-making. User types are many: local and national planners, environmental reserves managers, technical government agencies (water development, forestry, rural development, mining, and so on), development project initiators (international programmes, technical services, NGOs, local associations), farmers, socio-economic operators, and international agencies. Each user type can be associated with needs for adapted and pertinent information in terms of theme and spatial or time scales.

Thematic maps at various scales are the most easily accessible outputs for users; since its implementation, ROSELT makes them periodically available at the local scale (observatory level when the coverage is an ecological region) and at subregional/regional levels. Computer-assisted mapping and powerful geographical information systems (GIS) allow ROSELT to continuously diversify its outputs especially by crossing several data sources for causal relationship interpretations.

Other non-geographic data exist as well and are integrated into the SDI with their relevant spatial scope. These are mainly documentary type information related to the observatories activities as well as other regional studies; several types of reports are distinguished: methodological guides, data collection reports, introductory notes, scientific articles/papers, observatories reference states, evaluations of observatories activities and regional syntheses (ecology and socio-economic).

Based on their requests, ROSELT should provide the different users with a wide range of products: thematic and synthesis reports, raw or processed data, thematic maps, or environmental and desertification indicators. The ultimate goal of the SDI is to ensure the interactive usage and the easy access to these valuable resources (Figure 2).

\subsection{Used Technologies and Adopted Architecture}

ROSLET spatial data infrastructure is entirely developed using open source technologies (Free and Open Software: FOSS) [12] [13] with the open OGC (Open Geospatial Consortium) community standards and services to ensure interoperability among and between its components.

Data and information are stored in the spatial database which provides direct connections with the map server and the metadata server to publish this information online through client side interfaces: a map viewer and a geocatalogue to search and explore geospatial data.

These two main components are integrated into the ROSELT website using the content management system Joomla.

The established web component of ROSELT-SDI (Figure 3) is composed of three interoperable systems: 


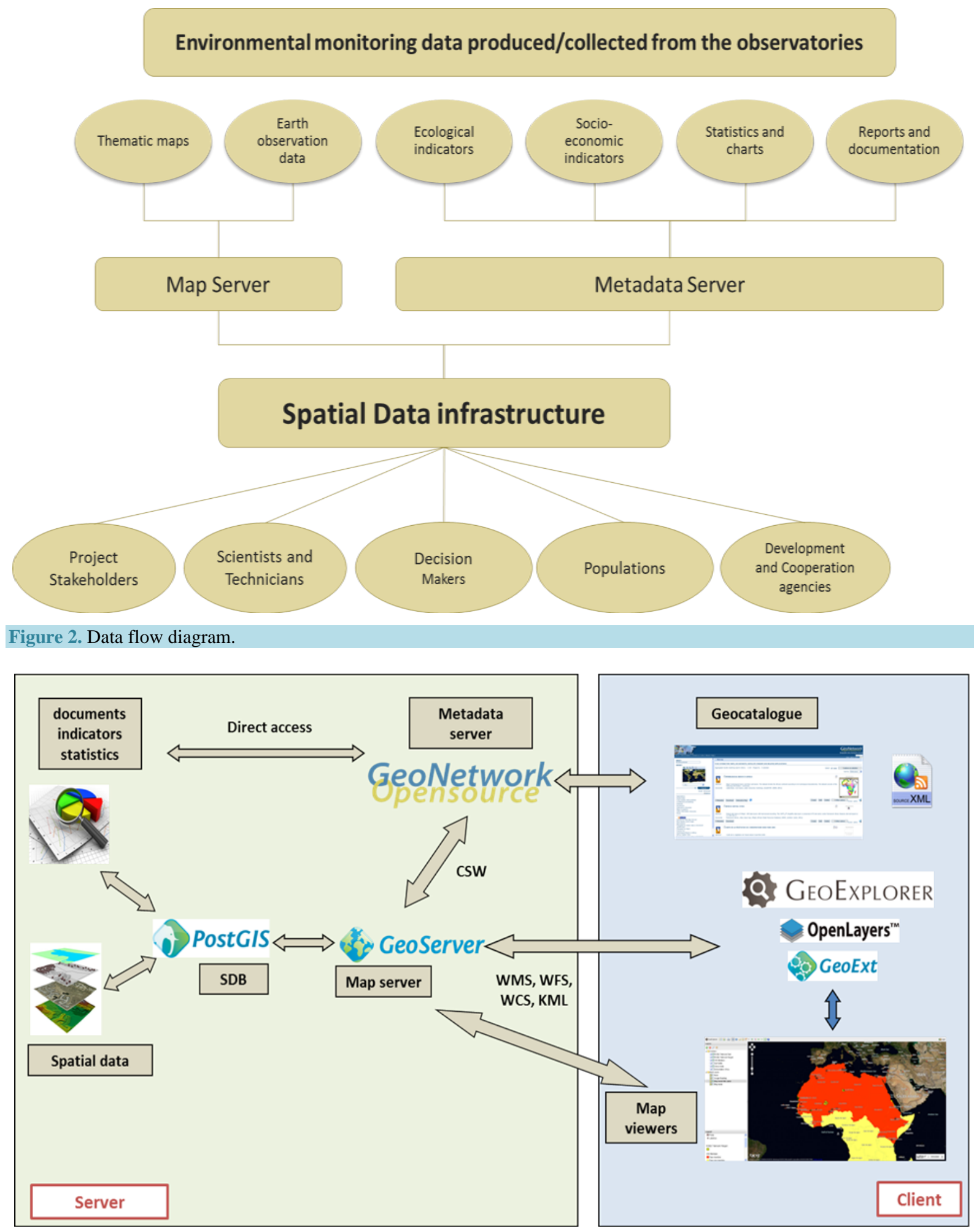

Figure 3. ROSELT-SDI architecture.

- Data storage System: a spatial database;

- Metadata management system: a Geocatalogue;

- Spatial data visualization system: a Map viewer. 


\section{Geospatial Metadata Management}

\subsection{Concepts}

Metadata (metacontent or data about data) is a file of information which captures the basic characteristics of a data and knowledge about one or more aspects of a specific resource. It represents the who, what, when, where, why and how of the resource. In other words, metadata provides systematic, understandable and deductive information about the content, structure, relationships, representation and context of use of a particular data set.

Geospatial metadata commonly document geographic digital data such as Geographic Information System (GIS) files, geospatial databases, and earth imagery but can also be used to document geospatial resources including data catalogs, mapping applications, data models and related websites. Metadata records include core library catalog elements such as Title, Abstract, and Publication Data; geographic elements such as Geographic Extent and Projection Information; and database elements such as Attribute Label Definitions and Attribute Domain Values.

\subsection{Geospatial Metadata Normalization}

Metadata standards are proposed for these specific types of resources (Geographic). A standard describes the characteristics and the properties to be assigned, and the values that those properties should take. Metadata can be structured into several levels, from a simple list of basic information to a complex and detailed document about a particular data set. Such standardization makes sharing information more reliable and universal [14].

Metadata about geographic data are currently, and since the early 90s, the subject of many researches aiming to normalize and set up common standards for those resources. Without being exhaustive, we'll mention the standards that are most often used in the field of geographic information. Most of them are based on proposals made by the FGDC1 since 1992 [FGDC 98]. Several other organizations are working in the same direction: the technical Committee 287 of CEN2: CEN TC 287 [CEN 96], the Technical Committee 211 of the ISO3: ISO TC 211 [ISO 03], the OpenGIS Consortium: [OpenGIS 98]. They're offering standards conceived around FGDC proposals, while developing their own areas of interest.

Now, the international standard ISO19115 geographic information-metadata is completed. The international initiative of the Technical Committee ISO/TC211 has capitalized previous experience of various national and European organizations, and proposes a metadata standard which will be adopted and used by the majority of international communities within the field of Geographic Information [15].

It seemed wise, for this project, to work with the internationally recognized "ISO 19115 geographic information-metadata" standard to ensure the interoperability of ROSELT metadata with similar various intern and extern systems.

\subsection{Setting up a Geocatalogue}

The key feature of ROSELT spatial data infrastructure is a web-based application that will give to users the possibility to search, explore and access to geospatial data through their metadata [16].

Making geographic information available, involves the development of systems using metadata to facilitate access for users, those systems are called metadata servers or simply Geocatalogue [17]. The need of disseminating spatial information on the Internet led to the creation of some solutions dedicated to this objective [18]. Furthermore, the flexibility of the Internet has helped to develop more powerful solutions, in this case, GeoNetwork was chosen.

GeoNetwork open source is a comprehensive Free and Open Source Software solution to manage and publish geospatial metadata and services based on international metadata standards and OGC specifications. The software is a part of the Open Source Geospatial Foundation's (OSGeo) software stack.

This tool provides an easy to use web interface to search geospatial data across multiple catalogs, combine distributed map services in the embedded map viewer and publish geospatial data using the online metadata editing tools [19] (Figure 4). Administrators have the option to manage users and group accounts, configure the server through web based and desktop utilities and schedule metadata harvesting from other catalogs [20].

The main functionalities of Geonetwork are: Geospatial data management, searching on local and distributed catalogues, upload and download data, import and export XML files, interactive web viewer, synchronization between distributed catalogues. 


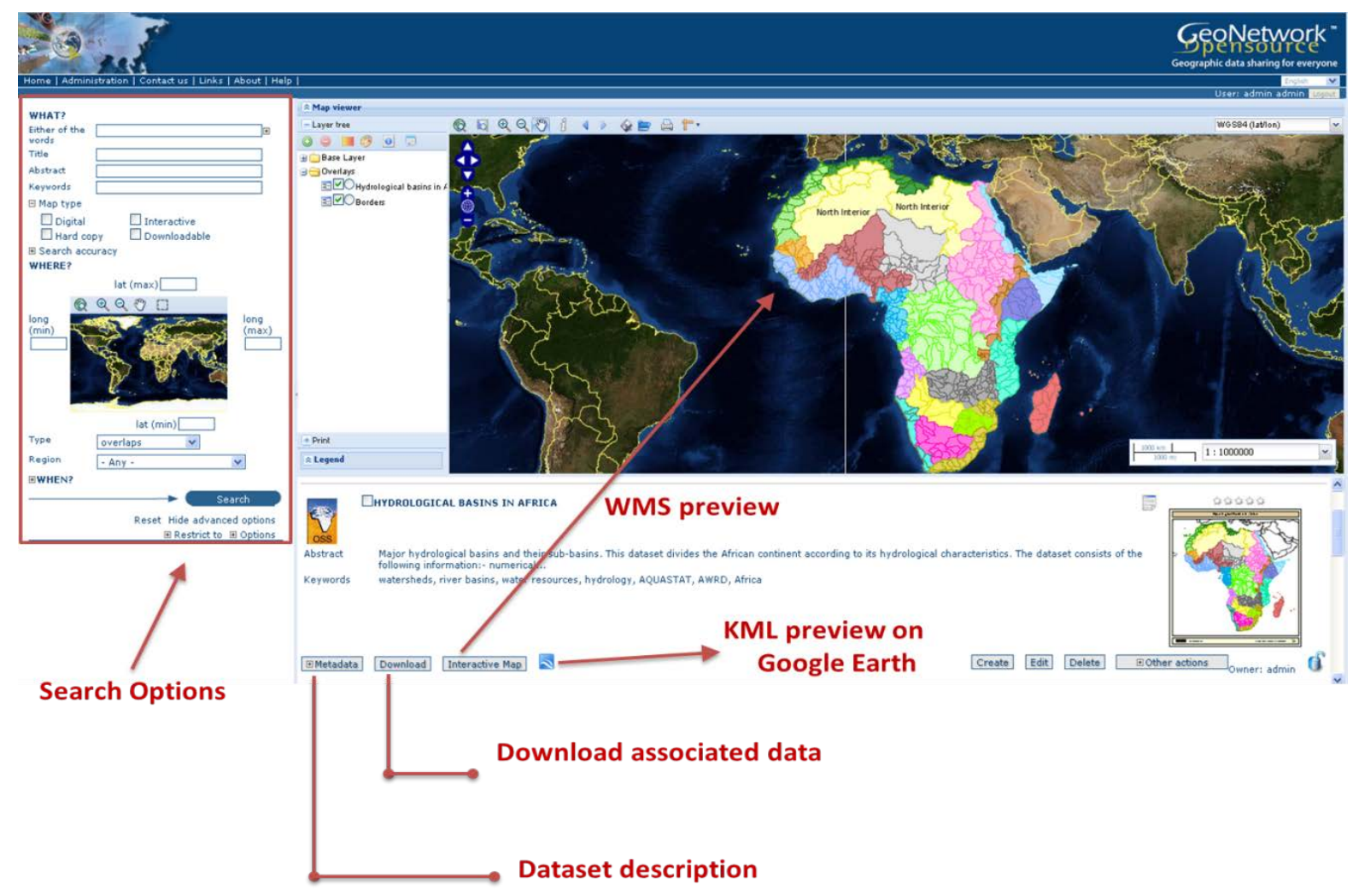

Figure 4. Searching for resources in GeoNetwork.

\section{Spatial Data Visualization}

\subsection{OGC Services and Formats}

Several technical standards defined by the Open Geospatial Consortium play an important role in the dissemination and processing of spatial data [21] [22]. In general, these standards (Table 1) describe communication protocols between data, servers that provide spatial services, and client software, which request and display spatial data. In addition, they define a format for the transmission of spatial data. The following OGC standards are identified as essential and are required to build an SDI [23].

\subsection{Overview of the Map Viewer Architecture}

At the bottom of this architecture there is a database system (PostGIS) to centralize the storage of ROSELT spatial information. There are server applications in the middle (GeoServer and GeoWebCache) that will connect with the database to publish vector and raster data using the OGC services (WMS, WCS...) [24], the role of the cache application is to accelerate and optimize map image delivery. And finally there's a user interface component on the top (GeoExplorer), it's a web-based map viewer developed using OpenLayers and GeoExt technologies to compose and publish maps.

\subsubsection{Zoom on Data and Its Storage}

The harmonization of geodata before publication is a prerequisite for the realization of spatial data infrastructures infrastructure. Spatial data used in this project comes in two main forms: vector and raster. These data represent some regional general information on the area of action (bioclimatic indices, agro-ecological zoning...) and the data collected during the environmental monitoring activities at ROSELT observatories (their delimitations, land cover and land use change, socioeconomic factors...). The first step is data preparation and harmonization using GIS desktop software (QGIS and UDIG in this case) to make sure that the data are spatially accurate, reliable and stackable (compatibility with other data). 
Table 1. Main OGC services and standard formats.

\begin{tabular}{|c|c|c|c|}
\hline Type & Acronym & Name & Purpose \\
\hline \multirow{5}{*}{ Services } & WMS & Web Map Service & $\begin{array}{l}\text { Provides maps as dynamic images, which may correspond to } \\
\text { the superposition of several spatial layers. }\end{array}$ \\
\hline & CSW & Catalog Service & Allows the publication of metadata and search catalogs. \\
\hline & WFS & Web Feature Service & Provides vector geographical features (geometry and attributes). \\
\hline & WCS & Web Coverage Service & $\begin{array}{l}\text { Supports retrieval of geospatial data as “coverages”: information representing } \\
\text { space/time-varying phenomena (Raster data, TIN...). }\end{array}$ \\
\hline & WPS & Web Processing Service & For geoprocessing services. \\
\hline \multirow{3}{*}{ Formats } & SLD & Style Layer Descriptor & $\begin{array}{l}\text { Allows users to define symbology and styles for spatial layers } \\
\text { (for WMS or WFS data). }\end{array}$ \\
\hline & GML & Geography Markup Language & Exchange format for vector geographical data. \\
\hline & KML & Keyhole Markup Language & A format for displaying geospatial data. \\
\hline
\end{tabular}

Now, to display it online, data should be stored somewhere the web server can access it [25]. This means a spatial database, PostgreSQL is used as a database management system (DBMS) with its spatial component PostGIS which allows taking into account geographically referenced objects.

\subsubsection{Zoom on the Map Server}

In simple terms, a map server takes a request from a web page and returns some data. It interprets bounding box requests to decide how much data to return, and ensures that it is in the correct projection. The map server used in ROSELT-SDI is Geoserver, written in Java and allows users to share and edit geospatial data. GeoServer was developed originally as the reference implementation of the OGC's WFS.

GeoServer connects to PostGIS and "reads" the list of available spatial tables; each table can be added to the server as a store then published as a layer.

To make data understandable and meaningful, it must be styled. Styling specifies color, thickness, and other visible attributes used to represent data on a map. In GeoServer, symbology is specified using a markup language created by the Open Geospatial Consortium called Styled Layer Descriptor or SLD [26]. The open source utility Atlas Styler enable to generate them using a visual interface.

Most mapping clients provide WMS (Web Map Service) data whenever they are requested, which can cause unnecessary processing and increase waiting time. GeoWebCache component "sits" between the server and the client to optimize this query/response operation by saving (caching) map images, or tiles, as they are requested in order to accelerate map image delivery.

\subsubsection{Zoom on the Map Viewer}

The client side is an interface for visualizing spatial data (Map Viewer) based on GeoExplorer, it's a web-based application developed by OpenGeo using OpenLayers, GXP and GeoExt to compose and publish maps. It allows adding WMS layers from ROSELT local Geoserver or any online server and the integration of cartographic APIs such as Google Maps and OpenStreetMap.

The map viewer is the last component of the Client/Server architecture to publish maps online.

This interface is made up of four zones: Map zone where the map is displayed; Layers panel where the list of added layers is displayed; Toolbar containing the navigation tools: (zoom, pan), export, and measurement tools, and Legend panel which displays styling information for any displayed layers in the layer panel.

\section{ROSELT/OSS New Website}

One of the main challenges of ROSELT is to share information related to the project topics and covering the sub-region, including data produced by the project.

The multi-stakeholder aspect of ROSLET project and the distribution of its users across the Sahara-Sahelian area (11 countries) require strategies to get the right knowledge to the right people at the right time and helping them to share and put information into action in ways that strive to improve organizational performance. 
An Information System, to be sustainable, should connect stakeholders with each other and provides tools to facilitate planning, collaboration, and systematic communication of information while giving an overview of the project, its objectives and developed the methodologies as well as general information on the observatories.

The functionalites of ROSELT project website has been improved and it has been transformed into an operational Knowledge portal which aims to provide a single point of entry through a common interface with information, resources and documentation based on the end-user's needs and specifications.

The two user interfaces of the spatial data infrastructure online component (the Geocatalogue and the map viewer) are integrated into the ROSELT/OSS official website. This web-based system allows users (especially the stakeholders) to explore the network through a single platform and to manage all information related to the project (Figure 5).

\section{Conclusions}

The Circum-Sahara, the action area of the Sahara and the Sahel Observatory, is primarily composed of arid, semi-arid and dry sub-humid countries characterized by harsh climatic conditions and highly fragile ecosystems. This region is at continental and global levels, among those experiencing the hardest pressures on natural resources. Desertification, biodiversity loss and climate change are major issues for this region and those problems cannot be efficiently treated at national levels. The fight against these phenomena must rely on data, indicators and knowledge updated and shared throughout the region by various stakeholders with an adequate coordination.

Centralized storage, format standardization and access facilitation are essential prerequisites, to valorize spatial data in planning and establishing environmental programs and projects. Indeed, the collection and dissemination of relevant, accurate and up to date information are actually of a paramount importance to improve the knowledge of the environment. Being able to access these data quickly is a prerequisite for building reliable and operational environmental monitoring devices.

A major goal of ROSELT/OSS is to provide these monitoring data and information to users, in the form of arguments, indicators and tools for various stockholders. ROSLET is mainly an intergovernmental context characterized by increased organizational complexities and therefore requires different information system development, management, and use practices. In such structures, spatial data infrastructures play an increasing role in data management and decision making at all levels.

The spatial data infrastructure for ROSELT/OSS program (ROSELT-SDI) developed in the context of this project aims to create an environment that enables a wide variety of users to easily access and retrieve spatial data

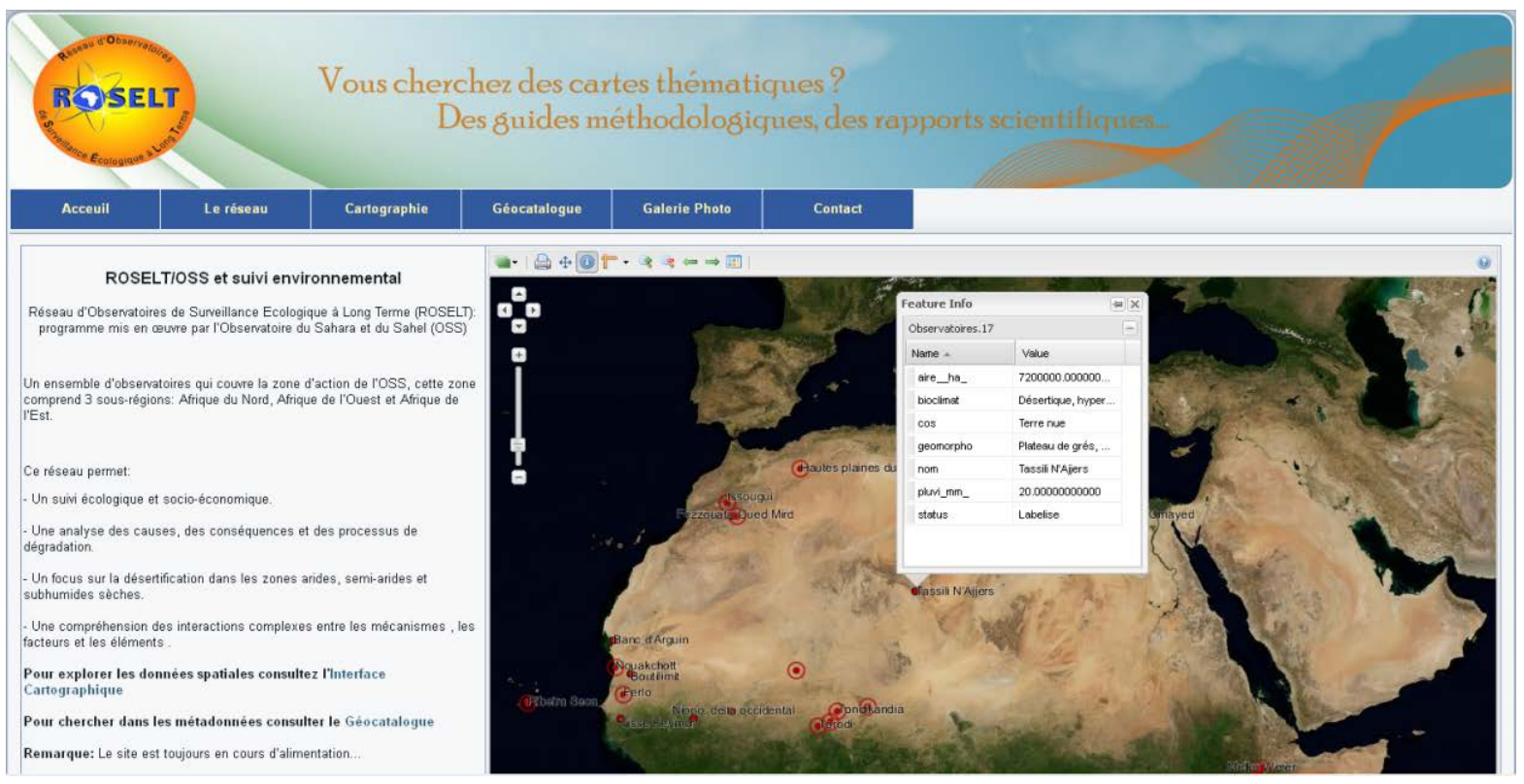

Figure 5. The new version of ROSELT website. 
sets in a complete, consistent, and secure manner. It can also be viewed as an environment in which all stakeholders, both users and spatial data producers, can cooperate with each other and utilize information and communications technologies [27].

International standards for spatial data and related services like catalogue's services provide us with appropriate interface to chain data management capabilities. From an end user perspective, ROSELT-SDI should organize information and data and distributes them via a single online access point; search and access to spatial data are necessary initial steps in SDI use. Indeed, the discovery of spatial data is facilitated through metadata catalogues and relies on metadata standards.

\section{List of ISO Standard}

ISO/TC 211: ISO 19115:2003 Geographic information-Metadata.

\section{References}

[1] Hamza, M.H., Added, A., Rodriguez, R., Abdeljaoued, S. and Ben Mammou, A. (2007) A GIS-Based DRASTIC Vulnerability and Net Recharge Reassessment in an Aquifer of a Semi-Arid Region (Metline-Ras Jebel-Raf Raf Aquifer, Northern Tunisia). Journal of Environmental Management, 84, 12-19. http://dx.doi.org/10.1016/j.jenvman.2006.04.004

[2] Tanser, F.C. and Le Sueur, D. (2002) The Application of Geographical Information Systems to Important Public Health Problems in Africa. International Journal of Health Geographics, 1, 4.

http://dx.doi.org/10.1186/1476-072X-1-4

[3] Fezzani, C., Essahli, W., Ravenel, H., Begni, G. and D’Herbes, J.M. (2002) OSS-Using Interdisciplinary Research and Modern Monitoring Technologies to Assess Ecosystems in African Dry Areas. The International Archives of the Photogrammetry, Remote Sensing and Spatial Information Sciences, 34, Part 6/W6.

http://www.isprs.org/proceedings/XXXIV/6-W6/papers/ossdares.pdf

[4] OSS Observatoire du Sahara et du Sahel (2004) Conception, organisation et mise en oeuvre de ROSELT/OSS, Collection ROSELT/OSS-Document Scientifique No. 1, 110 p. http://horizon.documentation.ird.fr/exl-doc/pleins_textes/divers10-02/010036815.pdf

[5] Filetti, M. and Gnauck, A. (2011) A Concept of a Virtual Research Environment for Long-Term Ecological Projects with Free and Open Source Software. Environmental Software Systems. Frameworks of Environment. IFIP Advances in Information and Communication Technology, 359, 235-244. http://dx.doi.org/10.1007/978-3-642-22285-6 26

[6] Clausen, C., Rajabifard, A., Enemark, S. and Williamson, I. (2006) Awareness as a Foundation for Developing Efficient Spatial Data Infrastructures. Shaping the Change, XXIII FIG Congress, Munich, 8-13 October 2006. http://vbn.aau.dk/files/5208076/CC_AR_SE_IW_FIG_2006.pdf

[7] D’Amore, F., Cinnirella, S. and Pirrone, N. (2012) ICT Methodologies and Spatial Data Infrastructure for Air Quality Information Management. IEEE Journal of Selected Topics in Applied Earth Observations and Remote Sensing, 5, 1761-1771. http://dx.doi.org/10.1109/JSTARS.2012.2191393

[8] Dragicevic, S. (2004) The Potential of Web-Based GIS. Journal of Geographical Systems, 6, 79-81. http://dx.doi.org/10.1007/s10109-004-0133-4

[9] Kraak, M. (2004) The Role of the Map in a Web-GIS Environment. Journal of Geographical Systems, 6, 83-93. http://dx.doi.org/10.1007/s10109-004-0127-2

[10] Global SDI (2009) SDI Cookbook. http://www.gsdidocs.org/GSDIWiki/index.php/Main_Page

[11] OGC Open Geospatial Consortium (2013) The OGC’s Role in Government \& Spatial Data Infrastructure.

[12] Brovelli, M., Mitasova, H., Neteler, M. and Raghavan, V. (2012) Free and Open Source Desktop and Web GIS Solutions. Applied Geomatics, 4, 65-66. http://dx.doi.org/10.1007/s12518-012-0082-4

[13] Câmara, C., Vinhas, L. and De Souza, C.M.R. (2009) Free and Open Source GIS: Will There Ever Be a Geo-Linux? Geospatial Free and Open Source Software in the 21st Century. Lecture Notes in Geoinformation and Cartography, 5, 229-245.

[14] Nogueras-Iso, J., Zarazaga-Soria, F.J. and Muro-Medrano, P.R. (2005) Geographic Information Metadata for Spatial Data Infrastructures, 2005.

http://www.springer.com/earth+sciences+and+geography/geographical+information+systems/book/978-3-540-24464-6

[15] ROSELT/OSS (2004) Système de circulation de l'information ROSELT: Définitions des métadonnées et élaboration des catalogues de référence, Collection ROSELT/OSS, Contribution Technique No. 12, Montpellier, 69.

[16] Litwin, L. and Rossa, M. (2011) Applications for Creating and Publishing Geoinformation Metadata, Geoinformation Metadata in INSPIRE and SDI. Lecture Notes in Geoinformation and Cartography, 2011, 113-126. 
http://dx.doi.org/10.1007/978-3-642-15862-9_5

[17] Farazi, F., Maltese, V., Giunchiglia, F. and Ivanyukovich, A. (2011) A Faceted Ontology for a Semantic Geo-Catalogue. The Semantic Web: Research and Applications. Lecture Notes in Computer Science, 6644, 169-182. http://dx.doi.org/10.1007/978-3-642-21064-8_12

[18] Stefanakis, E. (2012) Map Mashups and APIs in Education, Online Maps with APIs and Web Services. Lecture Notes in Geoinformation and Cartography, 1, 37-58. http://dx.doi.org/10.1007/978-3-642-27485-5_4

[19] Grill, S. and Schneider, M. (2009) Geonetwork Opensource as an Application for SDI and Education, GIS Ostrava. http://gis.vsb.cz/GIS_Ostrava/GIS_Ova_2009/sbornik/Lists/Papers/039.pdf

[20] GeoNetwork Opensource (2011) GeoNetwork User Manual (Release 2.6.4). http://mapas.mma.gov.br/geonetwork/docs/eng/developer/GeoNetworkDeveloperManual.pdf

[21] Michaelis, C.D. and Ames, D.P. (2009) Evaluation and Implementation of the OGC Web Processing Service for Use in Client-Side GIS. Geoinformatica, 13, 109-120. http://dx.doi.org/10.1007/s10707-008-0048-1

[22] OpenGeo (2009) The OpenGeo Architecture (Publication, White Paper). http://boundlessgeo.com/whitepaper/opengeo-architecture/

[23] Steiniger, S. and Hunter, A.J.S. (2012) Free and Open Source GIS Software for Building a Spatial Data Infrastructure, Geospatial Free and Open Source Software in the 21st Century. Lecture Notes in Geoinformation and Cartography, 5, 247-261. http://dx.doi.org/10.1007/978-3-642-10595-1 15

[24] Morris, S.P. (2010) Preservation of Geospatial Data: The Connection with Open Standards Development. Preservation in Digital Cartography. Lecture Notes in Geoinformation and Cartography, 2, 129-146. http://dx.doi.org/10.1007/978-3-642-12733-5_6

[25] Jolma, A., Ames, D.P., Horning, N., Neteler, M., Racicot, A. and Sutton, T. (2006) Free and Open Source Geospatial Tools for Environmental Modeling and Management. Proceedings of IEMSS 2006, 3rd Biennial Meeting of the International Environmental Modelling and Software Society, Burlington, Vermont.

[26] OGC Open Geospatial Consortium (2010) OGC Web Services Common Standard, OGC 06-121r9, Version: 2.0.0, Category: OGC® Implementation Standard, Arliss Whiteside and Jim Greenwood. http://portal.opengeospatial.org/files/?artifact id=38867

[27] Manisa, M. and Nkwae, B. (2007) Developing Botswana Spatial Data Infrastructure: From Concept to Reality, Towards the Development of Botswana, Spatial Data Infrastructure, Strategic Integration of Surveying Services, FIG Working Week 2007, Hong Kong, 13-17 May 2007. http://www.fig.net/pub/fig2007/papers/ts_1d/ts01d_04_manisa_nkwae_1376.pdf 